\title{
Biodegradation and Utilization of Organophosphorus Pesticide Malathion by Cyanobacteria
}

\author{
Wael M. Ibrahim, ${ }^{1}$ Mohamed A. Karam, ${ }^{1}$ Reda M. El-Shahat, ${ }^{2}$ and Asmaa A. Adway \\ ${ }^{1}$ Botany Department, Faculty of Science, Fayoum University, Fayoum, Egypt \\ ${ }^{2}$ Agricultural Research Center, Ministry of Agriculture, Egypt \\ Correspondence should be addressed to Wael M. Ibrahim; wms01@fayoum.edu.eg
}

Received 20 February 2014; Accepted 3 April 2014; Published 17 April 2014

Academic Editor: José Carlos Tavares Carvalho

Copyright (c) 2014 Wael M. Ibrahim et al. This is an open access article distributed under the Creative Commons Attribution License, which permits unrestricted use, distribution, and reproduction in any medium, provided the original work is properly cited.

Three strains of filamentous Cyanobacteria were used to study their growth and utilization of organophosphorus pesticide malathion. A sharp decrease in the growth of the algal strains was observed by increasing the concentration of malathion. Amongst them Nostoc muscorum tolerated different concentrations and was recorded as the highest efficient strain for biodegradation (91\%) of this compound. Moreover, carbohydrate and protein content of their cells overtopped the other strains especially at higher concentrations. The algal strains were further subjected to grow under P-limitation in absence and presence of malathion. Although, the algal growth under P-limitation recorded a very poor level, a massive enhanced growth and phosphorous content of cells were obtained when the P-limited medium was amended with malathion. This study clarified that N. muscorum with its capability to utilize malathion as a sole phosphorous source is considered as an inexpensive and efficient biotechnology for remediation of organophosphorus pesticide from contaminated wastewater.

\section{Introduction}

As a result of human impact, the levels of organic compounds found in surface water have increased in the recent decades. Of these organic compounds, pesticides are most commonly detected in all aquatic environments [1]. These pesticides are mainly used for agricultural purposes [2]. They enter the aquatic environment via runoff after being sprayed in agricultural fields and can potentially reach groundwater [3].

Malathion is a nonsystemic, wide spectrum organophosphate pesticide (OP), used to control insects on field crops, fruits, vegetables and also extensively used to prevent mosquitoes, flies, household insects, animal parasites, and head body lice [4].

Recent research shows that malathion has a variety of syndromes and effects including hepatotoxicity [5-7], human breast carcinoma [8], genetic damage [9], and disrupted normal hormone activity [10].

Not only are the chemical and physical methods of decontamination expensive and time-consuming, but also in most cases they do not provide a complete solution.
Bioremediation provides a suitable way to remove contaminants from the environment as, in most of the cases, OP compounds are totally mineralized by the microorganisms. Most OP compounds are degraded by microorganisms in the environment as a source of phosphorus or carbon or both [11].

Photoautotrophic microorganisms, such as Cyanobacteria, are used for wastewater treatment to remove nitrogen and phosphorus [12]. They have potential to remove various pollutants, such as dyes [13], heavy metals [14], and pesticides [15]. Therefore, this study is conducted to investigate the survival and tolerance of cyanobacterial isolates Anabaena oryzae, Nostoc muscorum, and Spirulina platensis with different concentrations of malathion, as well as evaluating their efficiency for removing and recovering this pesticide from contaminated wastewater.

\section{Material and Methods}

2.1. Algal Strains. The algal strains (Anabaena oryzae and Nostoc muscorum) were isolated from different water samples 
collected from Al-Fayoum Governorate, Egypt. Whereas, Spirulina platensis was obtained from Agricultural Research Center, Ministry of Agriculture, Giza, Egypt.

2.2. Chemicals. The organophosphorus pesticide used in this study is commercially available as Malathion, chemical name (O,O-dimethyl-S-[1,2-di(ethoxycarbonyl)ethyl]phosphorodithioate) was obtained from Kafr Elzayyat company, Egypt (98\% active ingredient).

2.3. Experimental Design. The selected algal isolates were batch-cultured in $500 \mathrm{~mL}$ Erlenmeyer flasks. Into each flask $200 \mathrm{~mL}$ of liquid culture media, BG11 medium [16] for $A$. oryzae and N. muscorum and Zarrouk medium [17] for $S$. platensis, was added. The initial inoculum was approximately $5 \times 10^{4} \mathrm{cell} / \mathrm{mL}$. Malathion was added to the culture medium to the final concentrations $0.02,0.2,2,20,50$, or $100 \mathrm{ppm}$. The culture flasks were kept under continuous illumination provided by daylight fluorescent tubes with an average light intensity of $40 \mu \mathrm{Em}^{-2} \mathrm{~s}^{-1}$ maintained constantly during the experiment. The flasks were incubated in a culture room at $28 \pm 1^{\circ} \mathrm{C}$ under continuous shaking of $80 \mathrm{rpm}$. Samples were taken after every four-day intervals up to fifty-two days for the estimation of the growth in terms of cell count. After 20 days, $50 \mathrm{~mL}$ of algal cultures was filtrated by centrifugation at $1500 \mathrm{rpm}$ for 20 minutes. The algal filtrate was used to determine malathion residues in the culture medium.

To obtain phosphorus-limited cultures, exponentially growing cells were inoculated into flasks containing medium with $1 / 10$ th of the original phosphorus concentration. The phosphorus-limited cells were cultured in a medium without and with different concentrations of malathion. Samples were taken after 20 days for estimation of cell count and phosphorus content in the tested algal cells.

2.4. Analytical Analysis. Different algal cultures were sonicated with Ultrasonic Homogenizer (Model: cp100, USA) to make them short fragments; $10 \mathrm{~mL}$ of algal solution was placed on vials containing $0.1 \mathrm{~mL}$ Lugol's solution [18]. Cell count was carried out using a standard haemocytometer under an Olympus BH-2 light microscope. Protein content of algal biomass was determined according to Lowry et al. [19]. For the determination of carbohydrate content in algal cells, the anthrone sulphuric acid method which was carried out by Fales [20] and adopted by Irigoyen et al. [21] was used. The total phosphorus content in the algal biomass was measured spectrophotometricallo at $720 \mathrm{~nm}$ according to Pierpoint [22]. Hewlett Packard Agilent GC System (Gas Chromatograph, USA) Model 6890 equipped with a flame photometric detector (FPD) with phosphorus filter was used for determination of malathion residues in the culture medium.

2.5. Statistical Analysis. Data were presented as mean of replicates from three runs and were analyzed statistically using Student's $t$-test for independent samples. Statements of significant differences were based on accepting $P \leq$ 0.05 . To validate the tolerance of algal strains, two identical

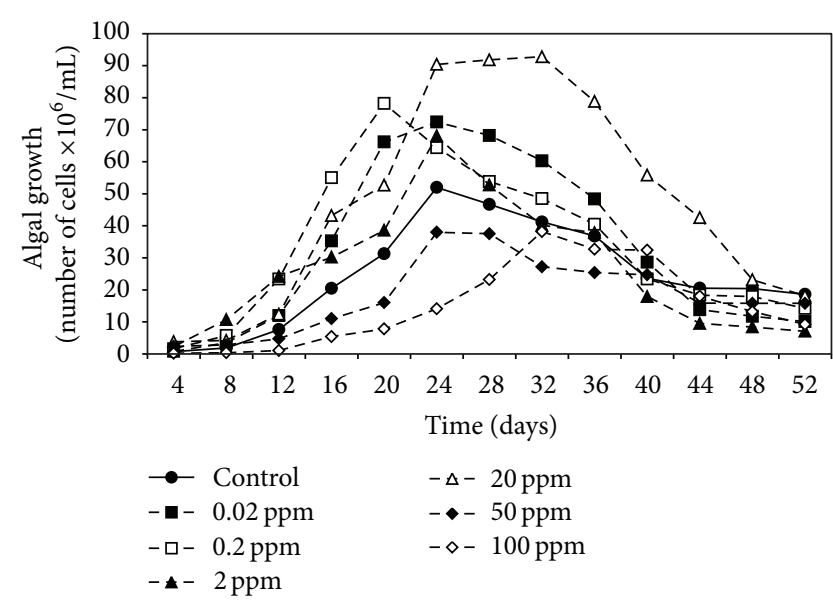

FIGURE 1: Effect of different malathion concentrations on the growth of A. oryzae.

series of linear regression curves were established for growth experiment.

\section{Results}

3.1. Effect of Malathion on Growth of Tested Algal Strains. Data in Figures 1, 2, and 3 demonstrated the effect of malathion concentrations on the growth of three cyanobacterial strains, A. oryzae, N. muscorum, and S. platensis. Obviously, an inverse relationship between malathion concentration and the algal growth was recorded. At low concentrations of malathion (0.02-20 ppm), the maximum growth of A. oryzae and N. muscorum was achieved within 24 days recording an increment of the total cell number by $41 \%$ and $75 \%$, respectively, compared with the untreated culture. At the same time, different malathion concentrations dramatically reduced the growth of $S$. platensis recording a reduction of the total cell count by $19 \%$ compared with the control treatment. Regression lines (Figure 4) indicated that N. muscorum was more tolerant than the other algal strains with different concentrations of malathion.

3.2. Effect of Malathion on Carbohydrate and Protein Content of Algal Cells. Data present in Figure 5 indicated that the treatment of $A$. oryzae and $N$. muscorum with different malathion concentrations caused a very high significant increase in total carbohydrate content with increasing concentrations of malathion and the highest carbohydrate content $(0.39$ and $1.09 \mathrm{mg} / \mathrm{g}$ dry weight, resp.) was recorded at $50 \mathrm{ppm}$ of malathion. At the same time, carbohydrate content of S. platensis was increased until $20 \mathrm{ppm}$ of malathion and then dramatically decreased as malathion concentration increased further.

Concerning protein content of algal strains, it is clear from Figure 6 that treatment of A. oryzae and N. muscorum with malathion significantly increased protein content of cells especially at higher concentrations (50 and $100 \mathrm{ppm}$ ). In case of S. platensis, lower concentrations of malathion ( 0.2 and $20 \mathrm{ppm}$ ) caused significant increase in protein content of 


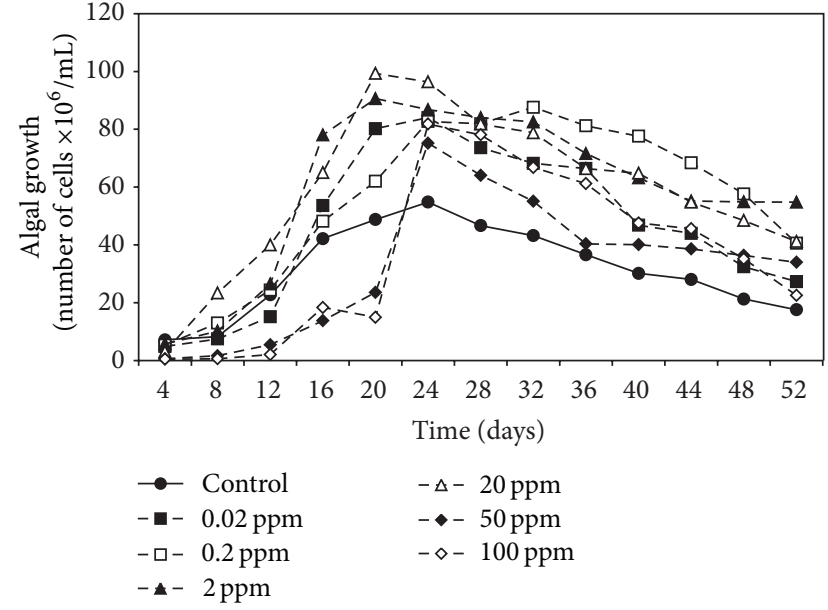

FIGURE 2: Effect of different malathion concentrations on the growth of N. muscorum.

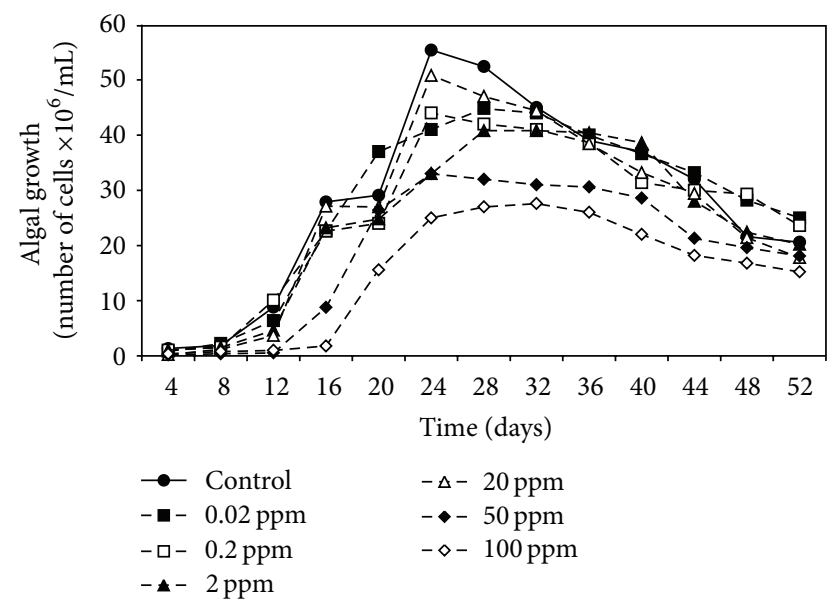

FIGURE 3: Effect of different malathion concentrations on the growth of S. platensis.

algal cells and high concentrations caused gradual decrease in protein content.

3.3. Biodegradation of Malathion by Different Algal Strains. Data present in Figure 7 illustrated that the three algal strains have the ability to biodegrade malathion at different concentrations. In general, $N$. muscorum was recorded as the highest efficient strain followed by $A$. oryzae and the lowest one was $S$. platensis with mean removal values of $91 \%, 65 \%$, and $54 \%$, respectively.

3.4. The Ability of Algal Strains to Utilise Malathion as Phosphorus Source. Algal strains were grown under phosphorus limitation condition in absence and presence of malathion in order to investigate their ability to utilise malathion as a sole phosphorus source. In absence of malathion, the growth of cells was markedly dwindled under phosphorus limitation recording a decrement in the total cell count by $75.5 \%$ compared with the unlimited cells (Table 1). On the other

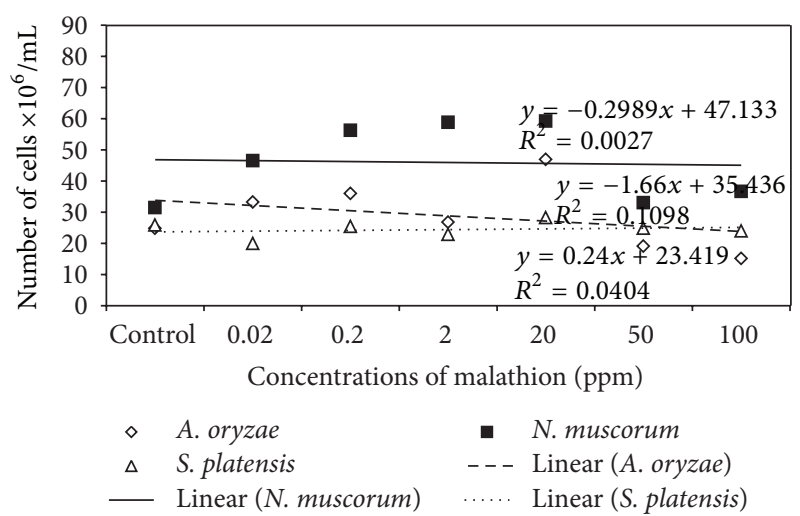

FIGURE 4: Regression lines of algal growth (expressed as cell count) of tested strains.

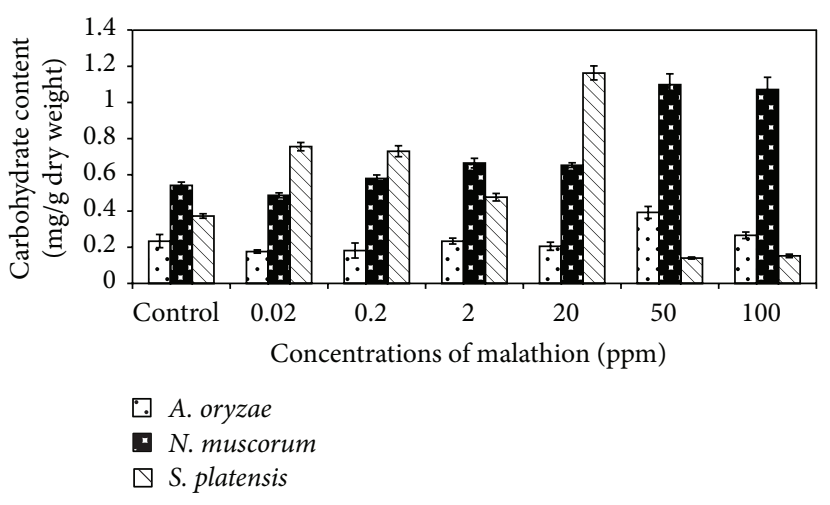

FIGURE 5: Effect of different concentrations of malathion on carbohydrate content of algal biomass. Data are the means of three replicates and error bars represent the standard errors of the means.

hand, when malathion was used as a sole phosphate source for the growth of algal strains under P-limitation condition, the greatest cell number was achieved recording 39\%, 52\%, and $20 \%$ increase more than the same conditions without the addition of malathion for A. oryzae, N. muscorum, and S. platensis, respectively.

The ability of algal strains to use malathion as phosphate source was confirmed by analysing the internal phosphorus content inside the algal biomass. Data in Table 2 revealed that the total phosphorus content of the cells that were cultured in media with P-limitation was very minor. When the limited culture was amended with malathion, the amounts of total phosphorus were increased to the same range spotted in the unlimited cells.

\section{Discussion}

It is clear from the results that the growth of algal strains was decreased as malathion concentration increased. This inverse correlation between malathion concentration and the algal growth agrees with Ibrahim and Essa [15] and Ghadai et al. [23] who studied the effect of different concentrations (1-400 ppm) of organophosphorus pesticides on the growth of seven cyanobacterial strains. They found that the low 

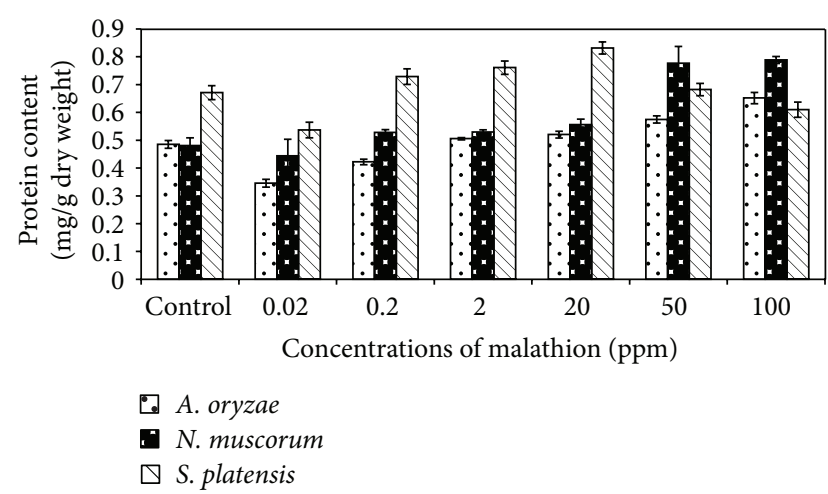

FIGURE 6: Effect of different concentrations of malathion on protein content of algal biomass. Data are the means of three replicates and error bars represent the standard errors of the means.

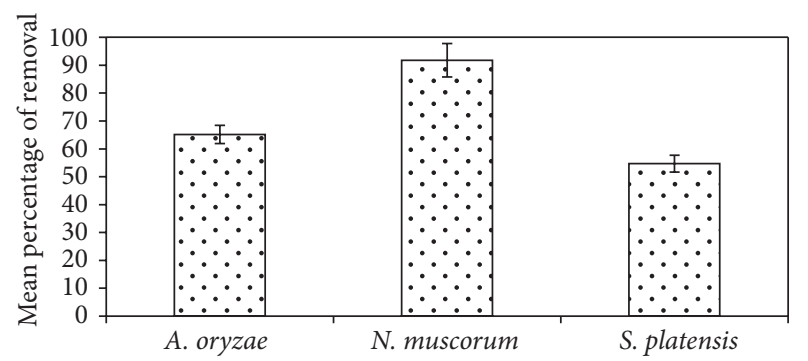

FIGURE 7: Efficiency of different algal strains to biodegrade malathion. Error bars represent the standard errors of the means.

TABLE 1: The growth of algal strains, expressed as cell count (number of cells $\times 10^{6} / \mathrm{mL}$ ), under unlimitation and P-limitation conditions with the addition of malathion.

\begin{tabular}{lccc}
\hline Algal strains & A. oryzae & N. muscorum & S. platensis \\
\hline Unlimitation & $24.7 \pm 2.9$ & $6.6 \pm 0.5$ & $8.8 \pm 0.1$ \\
P-limitation & $1.2 \pm 0.3^{\mathrm{a}}$ & $1.4 \pm 0.2^{\mathrm{a}}$ & $4.2 \pm 0.4^{\mathrm{a}}$ \\
P-limitation with different & & & \\
concentrations of & & & \\
malathion (ppm) & & & \\
$\quad 0.02$ & $4.4 \pm 0.5^{\mathrm{b}}$ & $2.1 \pm 0.3^{\mathrm{b}}$ & $6.4 \pm 1.1^{\mathrm{b}}$ \\
0.2 & $5.4 \pm 1.2^{\mathrm{b}}$ & $4.3 \pm 0.3^{\mathrm{b}}$ & $7.0 \pm 0.9^{\mathrm{b}}$ \\
2 & $5.6 \pm 0.6^{\mathrm{b}}$ & $4.8 \pm 0.5^{\mathrm{b}}$ & $7.2 \pm 0.9^{\mathrm{b}}$ \\
20 & $13.4 \pm 0.6^{\mathrm{b}}$ & $4.9 \pm 0.2^{\mathrm{b}}$ & $7.8 \pm 0.7^{\mathrm{b}}$ \\
50 & $22.6 \pm 0.8^{\mathrm{b}}$ & $7.1 \pm 0.1^{\mathrm{b}}$ & $8.2 \pm 0.7^{\mathrm{b}}$ \\
100 & $26.1 \pm 2.4^{\mathrm{b}}$ & $7.6 \pm 0.5^{\mathrm{b}}$ & $0.0 \pm 0.0^{\mathrm{b}}$ \\
\hline
\end{tabular}

Values are means of three replicates \pm standard errors.

${ }^{a}$ Significant decrease compared with unlimitation condition.

${ }^{\mathrm{b}}$ Significant increase compared with P-limitation condition.

concentrations stimulated the growth in terms of cell number and the higher concentrations dramatically reduced the algal growth. In this respect, extensive studies have been made concerning the inhibitory effects of organophosphorus pesticides on the cell count of different algal species [24-27].

The inhibitory effect of malathion could be attributed to the adsorption of this compound on the rich-lipid plasma
TABLE 2: Total phosphorus content (mg/g dry weight) of algal biomass under unlimitation and P-limitation condition with the addition of malathion.

\begin{tabular}{lccc}
\hline Algal strains & A. oryzae & N. muscorum & S. platensis \\
\hline Unlimitation & $10.1 \pm 0.1$ & $9.2 \pm 0.1$ & $19.8 \pm 0.1$ \\
P-limitation & $2.2 \pm 0.1^{\mathrm{a}}$ & $3.6 \pm 0.1^{\mathrm{a}}$ & $0.7 \pm 0.1^{\mathrm{a}}$ \\
P-limitation with different & & & \\
concentrations of & & & \\
malathion (ppm) & & & \\
$\quad 0.02$ & $6.9 \pm 0.0^{\mathrm{b}}$ & $11.2 \pm 0.0$ & $1.0 \pm 0.0$ \\
0.2 & $8.8 \pm 0.1^{\mathrm{b}}$ & $4.3 \pm 0.1^{\mathrm{b}}$ & $0.9 \pm 0.1^{\mathrm{b}}$ \\
2 & $11.6 \pm 0.1^{\mathrm{b}}$ & $4.7 \pm 0.1^{\mathrm{b}}$ & $0.9 \pm 0.1^{\mathrm{b}}$ \\
20 & $13.7 \pm 0.1^{\mathrm{b}}$ & $5.8 \pm 0.1^{\mathrm{b}}$ & $3.8 \pm 0.1^{\mathrm{b}}$ \\
50 & $14.0 \pm 0.1^{\mathrm{b}}$ & $6.6 \pm 0.1^{\mathrm{b}}$ & $4.1 \pm 0.1^{\mathrm{b}}$ \\
100 & $15.9 \pm 0.1^{\mathrm{b}}$ & $10.4 \pm 0.1^{\mathrm{b}}$ & $0.0 \pm 0.0^{\mathrm{b}}$ \\
\hline
\end{tabular}

Values are means of three replicates \pm standard errors.

${ }^{\mathrm{a}}$ Significant decrease compared with unlimitation condition.

${ }^{\mathrm{b}}$ Significant increase compared with P-limitation condition.

membranes of the algal cells, thus, altering the membranes permeability [28] and diminishing photosynthetic activity $[29,30]$ as well as increasing reactive oxygen species (ROS) during stress [25].

Figure 4 indicated that N. muscorum was more tolerant to different concentrations of malathion than the other algal strains. In agreement with these results Nayak et al. [27] reported that Nostoc sp. tolerated more than Anabaena sp. to organophosphorus pesticide monocrotophos and can grow up to $150 \mathrm{ppm}$. Also, Kumar et al. [31] study the tolerance of three cyanobacterial strains to endosulfan and record the tolerance in the order of N. muscorum $>A$. variabilis $>A$. fertilissima. Highest tolerance of $N$. muscorum could be as a result of its highest ability to biodegrade malathion (91\%) at different concentrations (Figure 7).

In general, data obtained from Figures 5 and 6 indicated that the total carbohydrate and protein content of algal biomass increased significantly with increasing malathion concentrations. Such a phenomenon may be due to the presence of some enzymes which can hydrolyse this organophosphorus compound and utilize malathion as nutrient sources $[15,32]$. Ghadai et al. [23] found that the organophosphorus pesticide diazinon stimulates carbohydrate content of blue green alga, A. cylindrica.

When algal strains were cultured in P-limited medium supplemented with different malathion concentrations, a highly significant growth was obtained compared with the cells that were grown under the same conditions without malathion addition which recorded a sharp reduction in their growth. In accordance with such results, Ibrahim and Essa [15] studied the effect of malathion on the growth of A. oryzae under phosphorus limited conditions. They found that the growth of $A$. oryzae under P-limitation recorded a very poor level and a massive enhanced growth was obtained when the P-limited medium was amended with malathion. The simulative effect of malathion on growth could be as a result of the increment of the available phosphorus, resulting from 
degradation of this compound by algal strains. Therefore, total phosphorus content of algal biomass was estimated in order to confirm their capability to utilise malathion as a phosphorus source. Results in Table 2 illustrated that the phosphorus content of the cells which grew under Plimitation and in presence of malathion was much higher than that found in cells cultured under the same conditions but without the addition of malathion revealing the capability of this strain to break down and utilize malathion as a sole phosphorus source. These findings agreed with Subramanian et al. [33] who attributed the growth enhancement of Cyanobacteria Aulosira fertilissima that was grown in the presence of malathion to their capability to utilize this compound as sole sources of phosphorus in the absence of inorganic phosphate from the medium.

\section{Conclusions}

The present study is the first evidence of the ability of $A$. oryzae, N. muscorum, and S. platensis to biodegrade and utilize malathion as a source of phosphorus. Overall, the data obtained highlight the efficiency of algal strains to grow under high concentrations of malathion with enhancement of biomass carbohydrate and protein content. Moreover, $N$. muscorum overtopped the other strains in removing more than $90 \%$ of malathion. Hence, work in this regard should continue to characterise the genetic and enzymatic components responsible for the utilization of malathion and other organophosphorus pesticides of this strain in order to evaluate its efficiency for the bioremediation of these environmental pollutants.

\section{Conflict of Interests}

The authors declare that there is no conflict of interests regarding the publication of this paper.

\section{References}

[1] U. Ali, J. H. Syed, R. N. Malik et al., "Organochlorine pesticides (OCPs) in South Asian region," Science of the Total Environment, vol. 476-477, pp. 705-717, 2014.

[2] M. A. Z. Chowdhury, I. Jahan, N. Karim et al., "Determination of carbamate and organophosphorus pesticides in vegetable samples and the efficiency of gamma radiation in their removal," BioMed Research International, vol. 2014, Article ID 145159, 9 pages, 2014.

[3] K. Bunzel, M. Kattwinkel, and M. Liess, "Effects of organic pollutants from wastewater treatment plants on aquatic invertebrate communities," Water Research, vol. 47, no. 2, pp. 597-606, 2013.

[4] V. L. Low, C. D. Chen, H. L. Lee et al., "Current susceptibility status of Malaysian Culex quinquefasciatus (Diptera: Culicidae) against DDT, propoxur, malathion, and permethrin," Journal of Medical Entomology, vol. 50, no. 1, pp. 103-111, 2013.

[5] A. S. Derbalah, "Efficacy of some botanical extracts against Trogoderma granarium in wheat grains with toxicity evaluation," The Scientific World Journal, vol. 2012, Article ID 639854, 9 pages, 2012.
[6] R. Josse, A. Sharanek, C. C. Savary, and A. Guillouzo, "Impact of isomalathion on malathion cytotoxicity and genotoxicity in human HepaRG cells," Chemico-Biological Interactions, vol. 209, pp. 68-76, 2014.

[7] R. Mesnage, N. Defarge, J. S. Vendômois, and G. E. Séralini, "Major pesticides are more toxic to human cells than their declared active principles," BioMed Research International, vol. 2014, Article ID 179691, 8 pages, 2014.

[8] L. S. Kjeldsen, M. Ghisari, and E. C. Bonefeld-Jørgensen, “Currently used pesticides and their mixtures affect the function of sex hormone receptors and aromatase enzyme activity," Toxicology and Applied Pharmacology, vol. 272, no. 2, pp. 453464, 2013.

[9] S. Karami-Mohajeri, M. Hadian, S. Fouladdel et al., "Mechanisms of muscular electrophysiological and mitochondrial dysfunction following exposure to malathion, an organophosphorus pesticide," Human \& Experimental Toxicology, vol. 33, no. 3, pp. 251-263, 2014.

[10] C. Taxvig, N. Hadrup, J. Boberg et al., "In vitro-in vivo correlations for endocrine activity of a mixture of currently used pesticides," Toxicology and Applied Pharmacology, vol. 272, no. 3, pp. 757-766, 2013.

[11] D. G. Karpouzas and B. K. Singh, "Microbial degradation of organophosphorus xenobiotics: metabolic pathways and molecular basis," Advances in Microbial Physiology, vol. 51, pp. 119-225, 2006.

[12] H. Wang, Z. Hu, B. Xiao, Q. Cheng, and F. Li, "Ammonium nitrogen removal in batch cultures treating digested piggery wastewater with microalgae Oedogonium sp," Water Science and Technology, vol. 68, no. 2, pp. 269-275, 2013.

[13] S. Rangabhashiyam, E. Suganya, N. Selvaraju, and L. A. Varghese, "Significance of exploiting non-living biomaterials for the biosorption of wastewater pollutants," World Journal of Microbiology and Biotechnology, 2014.

[14] W. M. Ibrahim, "Biosorption of heavy metal ions from aqueous solution by red macroalgae," Journal of Hazardous Materials, vol. 192, no. 3, pp. 1827-1835, 2011.

[15] M. W. Ibrahim and M. A. Essa, "Tolerance and utilization of organophosphorus insecticide by nitrogen fixing Cyanobacteria," Egyptian Journal of Botany, vol. 27, pp. 225-240, 2010.

[16] R. Rippka, J. Deruelles, and J. B. Waterbury, "Generic assignments, strain histories and properties of pure cultures of cyanobacteria," Journal of General Microbiology, vol. 111, no. 1, pp. 1-61, 1979.

[17] C. Zarrouk, Contribution a letuded une cyanophyceae. Infuence de divers facterurs physiques et chimiques sur la croissance et la photosynthese de Spirulina maxima (Stech.et Gardner) Geitler [Ph.D. thesis], Universite de Paris, Paris, France, 1966.

[18] G. W. Prescott, How to Know the Freshwater Algae, The Picture Key Nature Series, W.M.C. Brown Company Publishers, Dubuque, Iowa, USA, 3rd edition edition, 1978.

[19] O. H. Lowry, N. J. Rosebrough, A. L. Farr, and R. J. Randall, "Protein measurement with the Folin phenol reagent," The Journal of biological chemistry, vol. 193, no. 1, pp. 265-275, 1951.

[20] F. W. Fales, "The assimilation and degradation of carbohydrates by yeast cell," Journal of Biological Chemistry, vol. 193, pp. 113$124,1951$.

[21] J. J. Irigoyen, D. W. Emericha, and S. Diaz, "Water stress induced changes in concentrations of praline and total soluble sugars in nodulated alfalfa (Medicago sativa) plants," Physiology of Plant, vol. 84, pp. 55-60, 1992. 
[22] W. S. Pierpoint, "The phosphatase and metaphosphatase activities of pea extracts," The Biochemical journal, vol. 65, no. 1, pp. 67-76, 1957.

[23] A. K. Ghadai, S. Kumar, and D. K. Acharya, "Bio-Molecular assay of cyanobacteria on response to diazinon an Organophosphorus insecticide," International Journal of Chemical Research, vol. 2, no. 1, pp. 20-24, 2010.

[24] J. Ma, R. Zheng, L. Xu, and S. Wang, "Differential sensitivity of two green algae, Scenedesmus obliqnus and Chlorella pyrenoidosa, to 12 pesticides," Ecotoxicology and Environmental Safety, vol. 52, no. 1, pp. 57-61, 2002.

[25] F. I. Y. Mostafa and C. S. Helling, "Impact of four pesticides on the growth and metabolic activities of two photosynthetic algae," Journal of Environmental Science and Health B Pesticides, Food Contaminants, and Agricultural Wastes, vol. 37, no. 5, pp. 417-444, 2002.

[26] A. A. Fathi, "Some metabolic activities in the green alga Scenedesmus bijuga as affected by the insecticide trichlorfon," Protistology, vol. 3, pp. 92-98, 2003.

[27] B. Nayak, S. Bhattacharyya, and J. Sahu, "Photosynthetic response of two rice field cyanobacteria to pesticides," in Pesticides-Advances in Chemical and Botanical Pesticides, P. R. Soundararajan, Ed., chapter 7, pp. 151-168, Agricultural and Biological Sciences, 2012.

[28] C. Rioboo, O. González, C. Herrero, and A. Cid, "Physiological response of freshwater microalga (Chlorella vulgaris) to triazine and phenylurea herbicides," Aquatic Toxicology, vol. 59, no. 3-4, pp. 225-235, 2002.

[29] Y. Yamamoto and H. Tsukada, "Measurement of in situ specific growth rates of microcystis (cyanobacteria) from the frequency of dividing cells," Journal of Phycology, vol. 45, no. 5, pp. 10031009, 2009.

[30] N. Manikar, I. S. Kumar, K. Habib, and T. Fatma, "Biochemical analysis of Anabaena variabilis exposed to malathion pesticide with special reference to oxidative stress and osmolytes," International Journal of Innovative Research in Science, Engineering and Technology, vol. 2, no. 10, pp. 5403-5420, 2013.

[31] S. Kumar, K. Habib, and T. Fatma, "Endosulfan induced biochemical changes in nitrogen-fixing cyanobacteria," Science of the Total Environment, vol. 403, no. 1-3, pp. 130-138, 2008.

[32] S. XIE, J. LIU, L. LI, and C. QIAO, "Biodegradation of malathion by Acinetobacter johnsonii MA19 and optimization of cometabolism substrates," Journal of Environmental Sciences, vol. 21, no. 1, pp. 76-82, 2009.

[33] G. Subramanian, S. Sekar, and S. Sampoornam, "Biodegradation and utilization of organophosphorus pesticides by cyanobacteria," International Biodeterioration and Biodegradation, vol. 33, no. 2, pp. 129-143, 1994. 

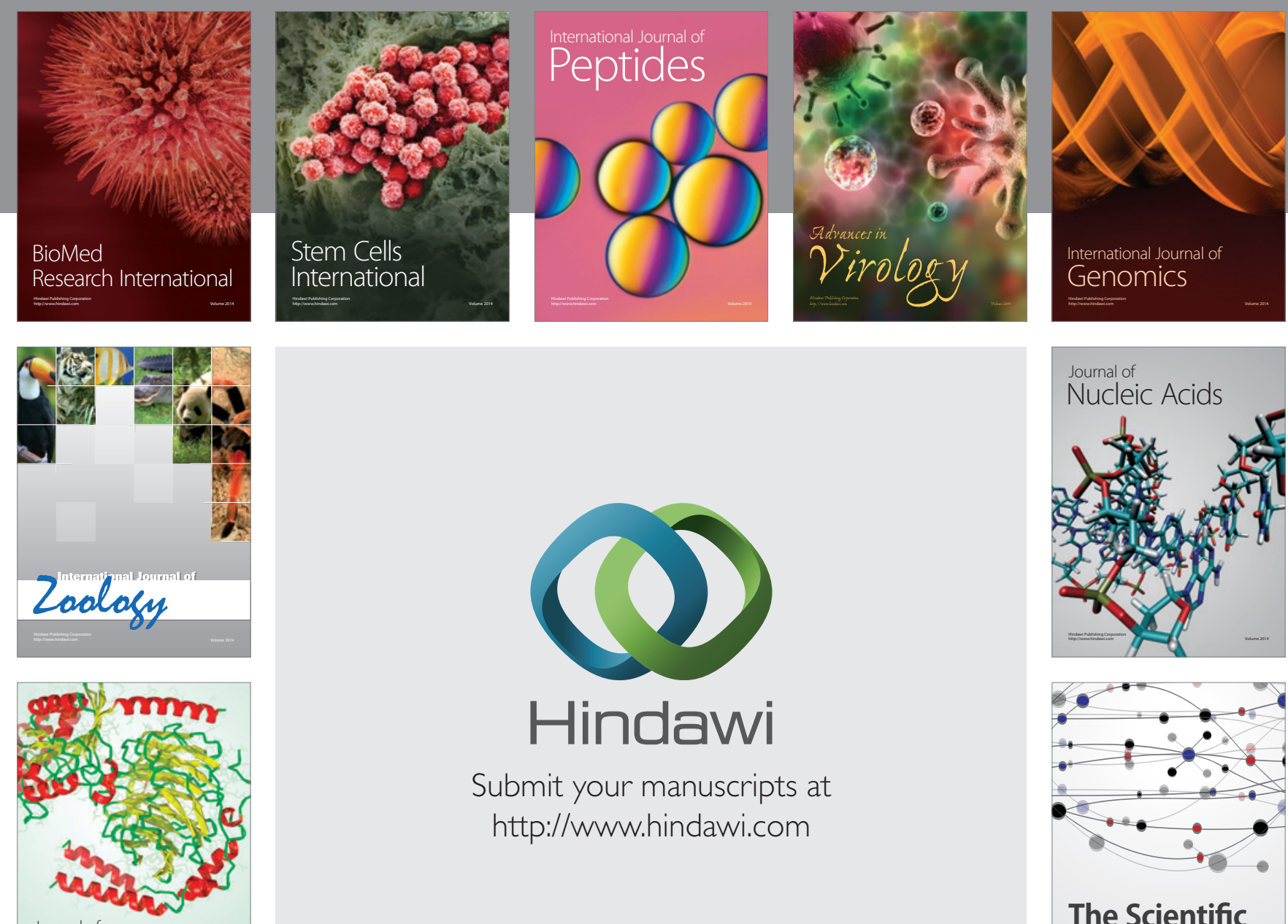

Submit your manuscripts at

http://www.hindawi.com

Journal of
Signal Transduction
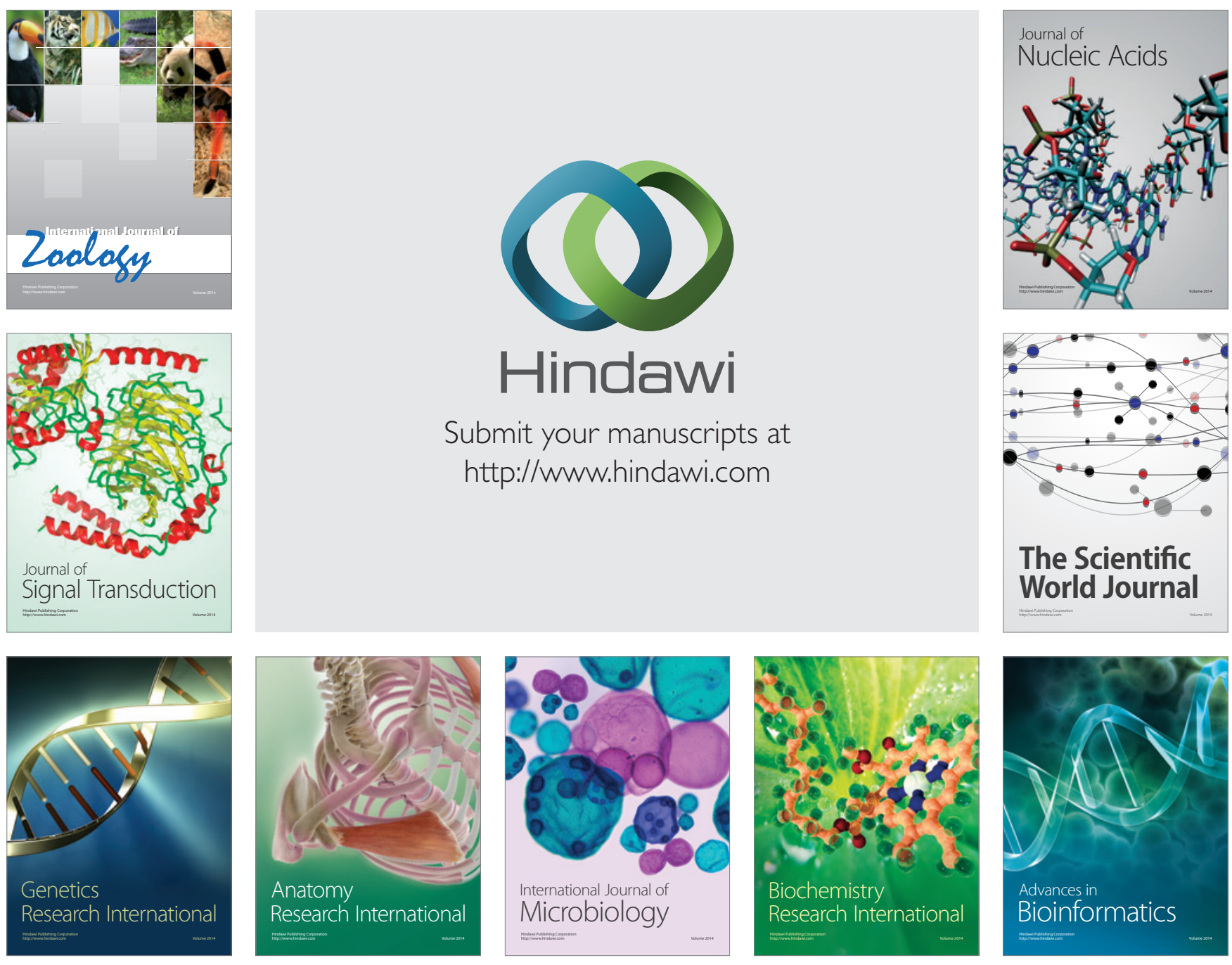

The Scientific World Journal
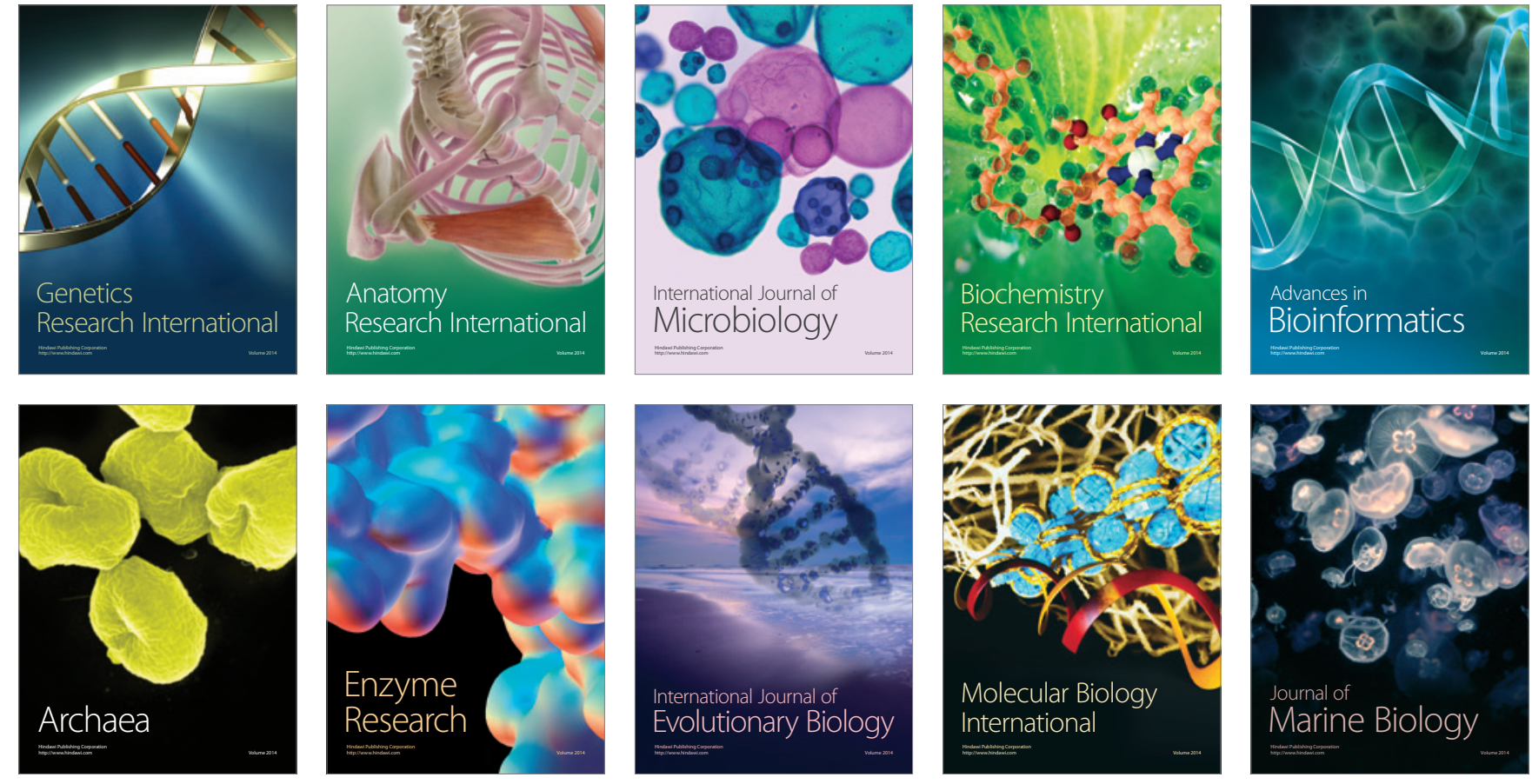